\title{
Ukraine invasion: safe corridor for medical supplies is urgently needed, says WHO
}

\section{Sally Howard}

The head of the World Health Organization has made an urgent call for a safe corridor in Ukraine "for humanitarian workers and supplies to reach people in need."

Speaking on 2 March, six days into the military assault by Russia, Tedros Adhanom Ghebreyesus said that urgently needed medical supplies were ready to be transferred into Ukraine from Poland. The problem was with logistics, however, as truck drivers were reluctant to take to the roads because of the continued bombing of the eastern and southern flanks of the country, said Jarno Habicht, WHO representative for Ukraine.

Oxygen remains one of the most urgent needs in Ukraine, said Michael Ryan, WHO executive director of emergency response. "It is difficult to watch nurses mechanically ventilating infants in basements," he said.

Last week 2000 people with covid were being treated with high flow oxygen, said Ryan, but with supplies dwindling it was uncertain how long treatment could last. Ghebreyesus said that at least three major oxygen plants in Ukraine have now closed and that WHO was "seeking ways of accessing oxygen from neighbouring countries and ways to deliver it safely to where it's needed."

WHO has said that it is verifying reports of multiple attacks on healthcare centres and professionals in Ukraine after a Russian ${ }^{1}$ ballistic missile carrying a cluster munition struck just outside a hospital in Vuhledar, a town in Donetsk region, on 24 February, followed two days later by artillery fire at Okhmatdyt children's hospital in Kyiv. Such attacks contravene the Geneva Convention, WHO said.

Ryan said that healthcare workers in Ukraine were a "shining example of what the healthcare system should be doing everywhere." But he reiterated the call for safe corridors for patients and supplies. "Something has to change to create conditions which can provide care," he said.

\section{From the frontline}

Elizaveta Plechistaya and her husband Pavlo, both hospital doctors in Kyiv, decided that they would remain in the Ukrainian capital despite the risk it represented to their one year old twin sons.

"We said to each other, "We have our work to do as doctors and we must be strong, for our family and for our colleagues'," Plechistaya told The BMJ. When she leaves home each morning for a central Kyiv hospital from the outskirts of the city where her sons are staying with her elderly parents for safety, she says goodbye to her family, thinking "will this be the last time?”
Like most doctors in Ukraine, Plechistaya is on a war footing: sleeping little, working in a hospital with blacked out windows, and taking shelter when air raid sirens sound.

The hospital where she and her husband work is short of insulin, morphine, and bandages, and has to deal with intermittent power outages. It is currently seeing 25 to 45 war traumas a day, although civilians with everyday health conditions are also a concern, said Plechistaya. "We have patients with diabetes who cannot get insulin because pharmacies are closed and what do people with acute appendicitis do in a city under siege?” she asks.

Oleksiy Rodyonov, a vascular surgeon at Kyiv's National Military Medical Center, told The BMJ that his hospital is taking in people wounded from neighbouring regions, including Kyiv Oblast and Chernihiv (parts of which are under Russian military control), but that getting them to the hospital is fraught with danger because of multidirectional bombardments.

Rodyonov is also worried about dwindling supplies as Russian advances sever supply routes. "We urgently need vacuum assisted closure devices for fast wound healing and consumables for these," he said. Water and power outages caused by infrastructure damage from the Russian bombardment and decoupling from the Russian grid ${ }^{2}$ are, for Rodyonov, the next most pressing concern, as well as food shortages. "We are making reserves of water and the people of Kyiv are helping us a lot with food donations," he said, adding that medics' morale remains high. "Our hospital is 266 years old and has served the people through many tragedies."

\section{British donations}

Dennis Ougrin, a Ukrainian British consultant psychiatrist, spoke to The BMJ from the border of Ukraine and Poland where he is part of an effort by Ukrainian British doctors to bring in medical supplies from the UK, including donations from NHS trusts. Priority items include tourniquets, anticoagulants, and first aid kits for the territorial army volunteers who do not have access to military supplies, he said.

Ougrin, who is in regular contact with Ukraine's first deputy minister of health, Oleksandr Komarida, said that the situation on the ground is "mixed and worrying."

"Kherson, in the south, is surrounded by troops and health services there are struggling; Khrakiv [the second city, in the east of Ukraine] is under bombardment and it's difficult to get supplies through; and at the moment the medical services in Kyiv, despite being under fire, are functioning. Our 
major worry is direct targeting of hospitals and medics," he said.

Bodan, a doctor in Kharkiv who did not want to give his real name, has spent the past few days preparing oncology patients for evacuation to the western city of Lviv. He told The BMJ that the hospital where he works has shifted to treating the war wounded and their postoperative bowel and neurological complications. For the moment drug and blood supplies are still getting through from the national healthcare system, he said, but water and food would soon become a problem.

"The city has two weeks supply of food and the hospital is making preparations for disrupted water supplies by storing water," he said, adding, "as doctors in Ukraine we are trained to deliver first, second, and third lines of treatment in the case of war. It is a tragedy that I am now putting this training to use."

\section{Covid-19}

Habicht said that the war had come when omicron infections in Ukraine had just past their peak in mid-February. He said that in Kyiv about $65 \%$ of the population was vaccinated, but beyond the capital vaccination rates were as low as $20 \%$, with many vulnerable people unvaccinated.

Tedros said that low rates of testing meant that there was likely to be significant undetected transmission of covid-19, which together with low vaccination coverage increased the risk of large numbers of people developing severe disease. "Mass population movements are likely to contribute further to transmission of covid-19, potentially increasing pressure on health systems in neighbouring countries," he said.

Additional reporting by Florence Long and Juliet Dobson

www.hrw.org/europe/central-asia/russia.

2 www.reuters.com/business/energy/ukraine-disconnect-its-power-grid-belarus-network-202202-26. 